\title{
AVALIAÇÃO DE TECNOLOGIAS EDUCACIONAIS DIGITAIS PARA A FORMAÇÃO DE PROMOTORES DE SAÚDE EM UMA EXPERIÊNCIA INTERPROFISSIONAL
}

\author{
Evaluation of Educational Technologies to Human Resources Formation \\ About Health Promotion in an Interprofessional Experience
}

\author{
Ana Claudia Camargo Gonçalves Germani'; Alfredo Almeida Pina de Oliveira²; \\ Anna Maria Chiesa ${ }^{3}$; Mario Ferreira Junior ${ }^{4}$
}

Resumo Objetivos: Descrever e analisar a utilização de recursos didáticos digitais em experiência semipresencial de formação interprofissional em promoção da saúde, com e sem apoio de tutoria. Materiais e Métodos: : A população foi constituída por 211 alunos de três edições do Curso "Práticas em Promoção da Saúde" da Faculdade de Medicina da USP. Os recursos, desenvolvidos com softwares livres, foram: blog, grupo de e-mails e palavras-cruzadas, oferecidos igualmente em 2007 e 2008, porém neste último ano associados a um trabalho de tutoria. $\mathrm{O}$ impacto na aprendizagem foi avaliado qualitativamente, por meio de grupo focal e quantitativamente, por meio de contadores próprios dos softwares de blog e grupo de e-mails. Resultados: Maior utilização das tecnologias ao longo do curso, sendo que a tutoria e a proximidade das provas aumentaram a média de visitas ao blog, do número de alunos participantes no grupo de e-mails e do número de mensagens enviadas. A avaliação quali-quantitativa mostrou impacto dos recursos didáticos no domínio do aprender a conhecer. Conclusão: A utilização do blog e grupo de e-mails aumentou durante o estudo, sobretudo com foco no conteúdo. Por outro lado, a tutoria somada aos recursos didáticos voltados à interação mostraram diferenças significativas nas formas de troca no grupo de e-mails, o que pode ser relacionado com o aprender a conviver.

Palavras-chave: tecnologia educacional, formação de recursos humanos, promoção da saúde, relações interprofissionais.

\begin{abstract}
Aims: To describe and analyze the use of digital learning resources in an experience of interprofessional education in health promotion, with and without support mentoring. Materials and Methods: The study population consisted of 211 students from three editions of Course "Practices in Health Promotion ", Faculty of Medicine, USP. Resources, developed with open source software, were: blog, emails based groups and crosswords, all offered in 2007 and 2008, but this last year associated with a mentoring. The impact on learning was assessed qualitatively through focus groups and quantitatively, through the own blog software and groups counters. Results: Increased use of technologies throughout the course and the mentoring and the proximity of assessment increased the average blog visits, the number of students participating in emails based groups and the number of messages sent. The qualitative and quantitative evaluation shows impact of educational resources in the field of learning to know. Conclusion: The use of the blog and the email based group increased during the study, especially focusing on the content. Moreover, mentoring added to the teaching resources aimed at interaction showed significant differences in the forms of exchange in the group e- mails, which may be related to learn to live together.

Keywords: Educational Technology, Human Resources Formation, Health Promotion, Interprofessional Relations
\end{abstract}

\footnotetext{
1. Médica, Professora do Departamento de Medicina Preventiva da Faculdade de Medicina da Universidade de São Paulo, São Paulo, Brasil; 2. Doutorando, Enfermeiro, Educador em Saúde Pública do Centro de Ensino e Pesquisa em Promoção da Saúde, Serviço de Clínica Geral, Hospital das Clínicas da Faculdade de Medicina da Universidade de São Paulo, São Paulo, Brasil; 3. Enfermeira, Professora Associada do Departamento de Enfermagem em Saúde Coletiva da Escola de Enfermagem da Universidade de São Paulo, São Paulo, Brasil; 4. Médico, Diretor do Centro de Ensino e Pesquisa em Promoção da Saúde, Serviço de Clínica Geral, Hospital das Clínicas da Faculdade de Medicina da Universidade de São Paulo, São Paulo, Brasil.
} 


\section{Introdução}

'Educar' vem do latim educare, por sua vez ligado a educere, verbo composto do prefixo ex (fora) + ducere (conduzir, levar), e significa literalmente 'conduzir para fora', ou seja, preparar o indivíduo para o mundo. Dowbor (2007) defende que nós, seres humanos, somos de certa forma, "programados" para aprender com o mundo, com as pessoas, durante as relações que construímos nas diferentes fases da vida.

Em relatório para a UNESCO - United Nations Educational Scientific and Cultural Organization, a equipe comandada por Jacques Delors traçou quatro domínios para a educação, ou seja, quatro formas de aprendizagem fundamentais ao longo da vida de um indivíduo, a saber:

10 Domínio - Aprender a conhecer: Além da aquisição de um repertório de saberes codificados, é preciso dominar os próprios instrumentos do conhecimento, ou seja, aprender para conhecer supõe aprender a aprender.

20 Domínio - Aprender a fazer: pôr em prática os conhecimentos, a fim de adquirir, não somente uma qualificação profissional, mas, competências que tornem a pessoa apta a enfrentar numerosas situações e a trabalhar em equipe.

$3^{\circ}$ Domínio - Aprender a viver juntos, aprender a viver com os outros: A educação deve utilizar duas vias complementares: a descoberta progressiva do outro e ao longo de toda vida, a participação em projetos comuns de cooperação.

$4^{\circ}$ Domínio - Aprender a ser: tem como objetivo melhor desenvolver a personalidade dos alunos para que assim possam agir com cada vez mais autonomia, de discernimento e de responsabilidade pessoal.

A Declaração de Hamburgo, publicada após trabalhos da $5^{\text {a }}$ CONFITEA - Conferência Internacional de Educação de Adultos (1997) reforçou que a educação de adultos inclui a educação formal, a educação não formal e o espectro da aprendizagem informal e incidental disponível numa sociedade multicultural, onde os estudos baseados na teoria e na prática devem ser reconhecidos.

Esse documento evidenciou que a educação de adultos e a educação de crianças e adolescentes são distintas, embora compartilhem a mesma premissa sobre a complementaridade e a continuidade do aprendizado ao longo de diferentes fases da vida. As variações de contextos socioeconômicos, ambientais e culturais somadas às necessidades pessoais e idiossincráticas refletem seu contexto de vida influenciam nessa nova visão de educação.

$\mathrm{Na}$ área da formação de profissionais para a saúde no contexto do Sistema Único de Saúde (SUS), a existência da Política Nacional de Educação Permanente em Saúde (PNEPS) representa uma proposta estratégica para transformar os processos de trabalho e produção em saúde.

Qualificar os cuidados no contexto da Educação Permanente em saúde requer processos formativos destinados a equipes multiprofissionais e práticas pedagógicas que incorporam o trabalho como contexto de aprendizagem ao problematizar a própria realidade e suas potencialidades e limites. Sugere-se a valorização da institucionalização desse processo por meio de pedagogias centradas na resolução de problemas, supervisões dialogadas e oficinas de trabalho.

A crescente necessidade de educação permanente pode beneficiar-se do ensino semipresencial. Ebert (2003) ressalta que o material didático é o "mediador" do processo de interação do aluno com os conteúdos curriculares e, por esse motivo, deve ser autoexplicativo, motivador e com possibilidade de adaptação a diversos tipos de aprendizagem.

Espera-se que o material didático prime pela interatividade, praticidade, autonomia além de mostrar coerência e consistência com os objetivos do curso. 
Entretanto, para que a internet cumpra seu papel de espaço integrador do indivíduo com o conhecimento é necessário que sejam utilizados recursos que possam ser compreendidos pelos potenciais usuários (Ebert, 2003).

A busca na internet por oportunidades de formação multi/interdisciplinar e interprofessional em promoção da saúde, complementares a graduação, apresenta iniciativas diversas, desde cursos breves, com curta duração (um a dois dias) em congressos, simpósios até atividades estendidas por um ano ou mais.

Desde 2004, a Faculdade de Medicina da USP oferece o Curso de atualização e especialização em "Práticas de Promoção da Saúde". Destinado a profissionais da área da saúde e outros profissionais envolvidos em programas de qualidade de vida e promoção da saúde.

O curso supracitado objetiva "capacitar os participantes no campo da promoção da saúde com conteúdo científico atualizado e sua aplicação prática, destacando programas de atuação em empresas e instituições de saúde pública e privada".

O acompanhamento da formação presencial de profissionais de saúde em promoção da saúde revelou dois desafios. O primeiro consistia na disseminação do modelo promotor de saúde ao maior número de profissionais, como forma de reorientar os serviços de saúde. O segundo focalizava o estímulo ao aprendizado colaborativo e permanente na perspectiva da educação de adultos.
Nesta direção foi desenvolvida pesquisa de doutorado para desenvolver materiais didáticos online a serem usados para educação em promoção da saúde (Silva, 2009). Buscaram-se recursos que favorecessem a comunicação entre alunos. Foram usados softwares gratuitos com a intenção de colaborar no incremento de habilidades relacionadas aos recursos digitais, comuns ao universo de trabalho dos profissionais da saúde.

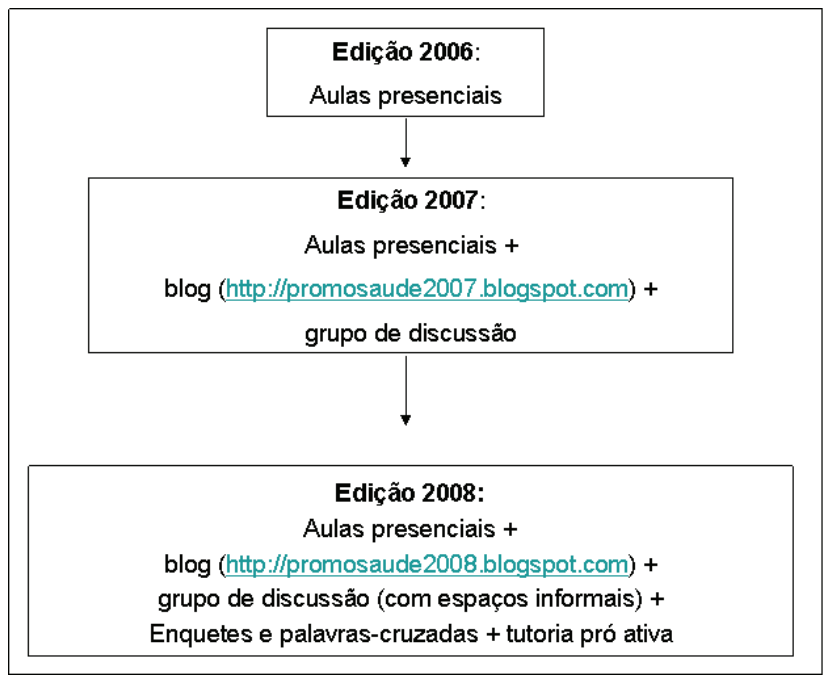

Quadro 1. Momentos de implementação dos recursos didáticos online, em curso de promoção da saúde

A oferta dos recursos foi estratificada em três momentos: a) 2006: apenas download dos slides das aulas presenciais; b) 2007: acesso a blog e grupo de e-mails; e c) 2008: além dos recursos anteriores, a pesquisadora desempenhou o papel de tutora (Quadro 2).

\begin{tabular}{|l|l|l|}
\hline Material Didático & Objetivo & Grau Pretendido de Interação \\
\hline $\begin{array}{l}\text { Webliografia, textos } \\
\text { e vídeos }\end{array}$ & $\begin{array}{l}\text { Selecionar a literatura relevante e torná-la acessível } \\
\text { aos profissionais de saúde, possibilitando a aquisição } \\
\text { de conhecimentos novos ou rápidas atualizações em } \\
\text { promoção da saúde e prevenção de doenças. }\end{array}$ & $\begin{array}{l}\text { Pequeno (troca de opiniões e comentários } \\
\text { sobre os links, textos e vídeos sugeridos). }\end{array}$ \\
\hline Grupo de e-mail & $\begin{array}{l}\text { Espaço assíncrono para discussões sobre tópicos dados } \\
\text { em aulas presenciais, além da troca de experiências } \\
\text { profissionais e pessoais. }\end{array}$ & $\begin{array}{l}\text { Convite a grande interação aluno-professor e } \\
\text { aluno-aluno, por superar a barreira temporal. }\end{array}$ \\
\hline Blog & $\begin{array}{l}\text { Quadro de avisos sobre andamento do curso e acesso a } \\
\text { webliografia. }\end{array}$ & $\begin{array}{l}\text { Interação unidirecional professor-aluno nos } \\
\text { avisos dados, interação aluno-professor nas } \\
\text { enquetes sugeridas semanalmente. }\end{array}$ \\
\hline Palavras Cruzadas & Testar retenção de conceitos-marcadores & Interação apenas com conteúdo teórico. \\
\hline
\end{tabular}

Quadro 2. Objetivos e grau pretendido de interação das tecnologias educacionais digitais. 


\section{Objetivo}

Descrever e analisar a utilização de recursos didáticos digitais em experiência semipresencial de formação interprofissional em promoção da saúde, com e sem apoio de tutoria.

\section{Método}

Acompanhando a atual discussão sobre as vantagens e desvantagens dos diversos métodos de pesquisa, tanto na área da saúde (Minayo, 1993; Serapioni, 2000) quanto na área da educação (Ludke e André, 1986; Alves-Mazzotti, 2001), foi desenvolvido aqui um trabalho quali-quantitativo.

\section{a) Avaliação Qualitativa}

O projeto completo envolveu dois recursos qualitativos: OSCE- Objective Structured Clinical Examination e grupo focal. Esse último será detalhado no presente estudo.

Na área de saúde, o grupo focal tem sido mais consistentemente usado a partir de meados dos anos 80 (Carlini-Cotrim, 1996). Weller (2006) valoriza o grupo focal como forma privilegiada de geração de representações sociais mediante a simulação de discursos.

Trata-se de uma técnica qualitativa que explora as opiniões coletivas. Nesse sentido, o propósito do grupo foi levantar as percepções, ideias, sentimentos, valores, experiências e dificuldades relacionados aos recursos didáticos interativos e ao processo ensino-aprendizagem no curso presencial de promoção da saúde.

Inicialmente, foi estruturado um roteiro, utilizando a"técnica do funil", ou seja, partiu-se de uma reflexão mais ampla, direcionada pelos quatro domínios da educação defendidos por Delors (Gondim, 2002). Foi sugerido o aprofundamento progressivo, finalizado com a construção de uma cena de utilização de um recurso didático interativo.

A coleta de dados por meio da descrição de cenas permitiu o detalhamento dos facilitadores e barreiras para o uso dos recursos didáticos digitais entre os participantes da pesquisa.

Nos textos consultados (Gondim 2002; lervolino e Pelicioni, 2001), o tamanho do grupo varia entre quatro e 10 pessoas. Foram organizados, então, três grupos, um para cada ano do curso, com o intuito de manter a homogeneidade relacionada à exposição aos recursos online.

Foram sorteados 15 alunos de cada uma das turmas do curso presencial, procurando envolver homens e mulheres, com diferentes idades e formações. Entre os 45 alunos sorteados e convidados por e-mail, 15 (33\%) participaram nos três grupos focais.

A pesquisadora principal exerceu o papel de moderadora dos grupos focais. As falas foram gravadas e o material obtido transcrito, para que então se procedesse à análise de conteúdo (Carlini-Cotrim, 1996). Segundo Camelo (2006), a categorização é o desmembramento do texto em unidades, segundo reagrupamentos analógicos e tem como função fornecer uma representação simplificada dos dados brutos.

A construção das categorias identificou temas importantes (mencionados por pouco tempo ou poucas pessoas no grupo, mas com grande significado) e temas interessantes (assuntos envolventes para grande parte do grupo).

\section{b) Avaliação Quantitativa}

As ferramentas Google Analytics ${ }^{\circledast}$ e Google Groups ${ }^{\circledast}$ permitiram o mapeamento do uso dos recursos digitais. O primeiro é um recurso gratuito, disponibilizado pelo Google, usado para acompanhar a quantidade de visitas por dia, o tempo médio de visitas e o número de páginas visitadas nos blogs. As enquetes, oferecidas em 2008, tinham contagem automática de votos.

Os recursos administrativos do grupo de e-mails organizados no Google permitiram acompanhar o número de mensagens enviadas, horário do envio e identificar os remetentes envolvidos. Foi colocado um contador 
gratuito para a mensuração do número de downloads do recurso palavras cruzadas.

Fernandes (2008) estudou em sua dissertação as trocas interindividuais em grupo de e-mails criado como parte da graduação de pedagogia, na Universidade Federal do Rio Grande do Sul.

A partir da concepção de Piaget, a autora acima defendeu que comunidades virtuais de aprendizagem dependem da cooperação, descentração (capacidade de se desprender de um aspecto delimitado do real, considerado até então, para se considerar outros aspectos e finalmente coordená-los) e reciprocidade (capacidade de situar seu ponto de vista entre outros possíveis) para construção do conhecimento. Como forma de transportar estes conceitos para a comunicação escrita, ela criou três tipos de trocas interindividuais (Fernandes, 2008):

- Troca inicial - caracterizada pelo envio de uma mensagem a outro participante ou ao grupo. A presença de "um turno" sinaliza a não continuidade da troca, demonstrando que os outros participantes não correspondem ao envio da mensagem.

- Troca com continuidade restrita - caracterizada pelo envio de uma mensagem a um participante ou ao grupo, seguido de outra mensagem direcionada à anterior sinalizando a continuidade da troca, ou seja, presença de dois turnos.

\section{- Troca com continuidade ampla - caracterizada} pelo envio de mais de uma mensagem ao mesmo participante com a presença de mais de dois turnos, pois é mantida a sequência do assunto.

Por acreditar que o grupo de e-mails aproxima-se de uma comunidade virtual de aprendizagem, complementar ao espaço presencial, tal classificação foi usada para analisar os registros de participação dos alunos nas discussões nos grupos criados em 2007 e 2008.

Este projeto foi submetido e aprovado pela Comissão de Ética para Análise de Projetos de Pesquisa CAPPesq do Hospital das Clínicas e da Faculdade de Medicina da Universidade de São Paulo, protocolo de pesquisa no 1013/06.

\section{Resultados}

A Tabela 1 mostra as características sociodemográficas dos 211 alunos inscritos no curso presencial de promoção da saúde, nos anos de 2006 a 2008. A maioria (177; 84\%)

\begin{tabular}{|c|c|c|c|c|c|c|c|c|}
\hline & \multicolumn{2}{|c|}{2006} & \multicolumn{2}{|c|}{2007} & \multicolumn{2}{|c|}{2008} & \multicolumn{2}{|c|}{ TOTAL } \\
\hline & $\mathbf{n}$ & $\%$ & n & $\%$ & $\mathbf{n}$ & $\%$ & $\mathbf{n}$ & $\%$ \\
\hline \multicolumn{9}{|l|}{ Gênero } \\
\hline Masculino & 65 & 84,4 & 61 & 81,3 & 51 & 86,4 & 177 & 83,9 \\
\hline Feminino & 12 & 15,6 & 14 & 18,7 & 8 & 13,6 & 34 & 16,1 \\
\hline \multicolumn{9}{|l|}{ Faixa Etária* } \\
\hline Menor de 25 anos & 4 & 5,2 & 6 & 8,0 & 2 & 3,4 & 12 & 5,7 \\
\hline $25-40$ & 29 & 37,7 & 43 & 57,3 & 32 & 54,2 & 104 & 49,3 \\
\hline Maior de 40 anos & 23 & 29,9 & 21 & 28,0 & 24 & 40,7 & 68 & 32,2 \\
\hline \multicolumn{9}{|l|}{ Formação** } \\
\hline Enfermagem & 21 & 27,3 & 19 & 25,3 & 21 & 35,6 & 61 & 28,9 \\
\hline Medicina & 24 & 31,2 & 18 & 24,0 & 16 & 27,1 & 58 & 27,5 \\
\hline Outras Áreas da Saúde † & 18 & 23,4 & 28 & 37,3 & 19 & 32,2 & 65 & 20,4 \\
\hline Áreas Humanas e Exatas $† \dagger$ & 11 & 14,3 & 10 & 13,3 & 2 & 3,4 & 23 & 10,9 \\
\hline \multicolumn{9}{|l|}{ Tempo de Formatura*** } \\
\hline Menor que 5 anos & 15 & 27,8 & 15 & 23,8 & 12 & 20,3 & 42 & 24,3 \\
\hline 5 a 9 anos & 11 & 20,4 & 16 & 25,4 & 13 & 22,0 & 40 & 23,1 \\
\hline 10 anos ou mais & 28 & 51,9 & 32 & 50,8 & 31 & 52,5 & 91 & 52,6 \\
\hline
\end{tabular}

Tabela 1. Distribuição da amostra de acordo com gênero, faixa etária, formação e tempo de formatura (211 alunos)

* Dados faltantes: 21 (2006), 5 (2007) e 1 (2008)

** Dados faltantes: 3 (2006) e 1 (2008)

*** Dados faltantes: 23 (2006), 12 (2007) e 3 (2008) † nutrição, educação física, fisioterapia, fonoaudiologia, psicologia, serviço social †† engenharia, jornalismo, contabilidade, administração 
era do gênero feminino e a média \pm desvio padrão de idade foi $36,0 \pm 9,0$ anos, sem diferença estatisticamente significante na comparação entre os três anos $(p=0.178)$.

As turmas eram constituídas, principalmente, por profissionais ligados à área da saúde, sobretudo da enfermagem $(61 ; 28,9 \%)$ e medicina $(58 ; 27,5 \%)$. A maior parte dos alunos $(91 ; 52,6 \%)$ possuía 10 anos ou mais de formado.

\section{Qualitativo}

As cenas descritas pelos participantes trouxeram dois conteúdos centrais, comuns aos três anos: o uso dos recursos digitais como novidade na formação do profissional da saúde, sendo reconhecido o potencial dos recursos ao final formal das aulas, e a dificuldade inerente às faixas etárias mais velhas para adesão aos recursos didáticos (Quadro 3).
Como ilustrado pelos depoimentos a seguir, os recursos online foram percebidos como um suporte original para a formação em promoção da saúde, com reflexos na aquisição de conhecimento em outras áreas.

P5 (2006:) "...baixei as aulas, sem problemas. Até hoje uso o material. Tive boas surpresas, porque entrava para pegar as aulas e me deparava com mais material, com as leituras complementares. Faz toda diferença."

P8 (2007): "O suporte online muda competências de quem estiver interessado. Abre caminhos. O curso te provoca, te ensina a pensar."

P9 (2007): "...eu nunca tinha ouvido falar desta parte esquisita, online, aí, você começa a ver que o negócio é muito bom. Agora eu estou entrando em outros cursos online. Acabei de fazer um de quimioterapia."

\begin{tabular}{|c|c|c|}
\hline Tema proposto & Tópicos discutidos & Edição do curso \\
\hline \multirow[t]{4}{*}{ Uso dos recursos didáticos digitais } & Recursos didáticos digitais como novidade & \multirow[t]{2}{*}{2006,2007 e 2008} \\
\hline & Desafio para faixa etária mais velha & \\
\hline & Insegurança & 2007 e 2008 \\
\hline & Frustração / Satisfação & 2008 \\
\hline \multirow[t]{3}{*}{ Aprender a conhecer } & Contato com fontes científicas confiáveis* & \multirow[t]{2}{*}{2006,2007 e 2008} \\
\hline & Contato com novos temas & \\
\hline & Contato com novas formas de aprender & Especialização \\
\hline \multirow[t]{2}{*}{ Aprender a fazer } & $\begin{array}{l}\text { Observação de atividades presenciais do CPS HCF- } \\
\text { MUSP (atendimentos e grupos) }\end{array}$ & 2006,2007 e 2008 \\
\hline & Simulação de atendimentos & Especialização \\
\hline \multirow[t]{4}{*}{ Aprender a conviver } & Tolerância frente a diversidade de alunos & \multirow[t]{2}{*}{2006,2007 e 2008} \\
\hline & Impacto positivo nas práticas profissionais & \\
\hline & Impacto positivo na convivência familiar & 2006 \\
\hline & Familiarização com novos temas & 2008 \\
\hline \multirow[t]{3}{*}{ Aprender a ser } & Reflexão sobre auto-cuidado & \multirow[t]{2}{*}{2006,2007 e 2008} \\
\hline & Impacto positivo nas práticas profissionais & \\
\hline & Impacto positivo na convivência familiar & 2006 \\
\hline
\end{tabular}

* depoimentos espontâneos sobre recursos didáticos digitais oferecidos como complemento do conteúdo presencial.

Quadro 3. Resumo das categorias observadas na análise de conteúdo, produzidas nos grupos focais, de acordo com tema proposto e edição do curso. 
A idade foi mencionada como fator crítico para a baixa familiaridade com os recursos online. É interessante apontar que durante a discussão sobre o tema surgiram citações sobre formas de superar tal obstáculo, como o acionamento da rede de amigos com maior facilidade (usado por duas participantes) e a percepção de que um manual de instruções, impresso, que simule o passo a passo da utilização e estivesse disponível a todo momento seria decisivo para novas tentativas de uso.

Particularmente, no grupo de 2008, a utilização do grupo de e-mails despertou dois posicionamentos antagônicos: um positivo que ressalta a oportunidade benéfica da troca com o grupo e o outro com decepção, experiência desagradável justamente pela falta de interação com os colegas.

P14 (2008): "Tenho a prática de fazer resumo da matéria e a possibilidade de passar para todo mundo foi positivo. Tive medo da censura, mas com a receptividade do pessoal ajudou bastante. Descobri uma coisa em mim, que eu mesma não dava tanta importância... Se não tivesse essa ferramenta [referindo-se ao grupo de e-mail] eu não poderia colocar isso em prática".

P10 (2008): "Fiquei frustrada, pois sou superconectada e eu mandava tudo e ninguém respondia. Por que será? Depois eu descobri que muita gente tinha dificuldade, não era hábito."

Ainda em relação ao uso dos grupos de e-mail, foram observados dois posicionamentos entre os participantes de 2007 e 2008: necessidade de maior comprometimento dos colegas, ou seja, envolvimento por parte dos demais alunos, e a autocensura como obstáculo importante para a expressão escrita.

P7 (2007): “... infelizmente, faltou comprometimento. A atividade virtual deveria ser obrigatória!"
P9 (2007): "... tive muita dificuldade e medo de fazer besteira, deixar um comentário e receber uma crítica, de não ser bem entendida".

Vale salientar que entre os 10 participantes dos grupos focais referentes a 2007 e 2008, e, portanto, "expostos" ao grupo de e-mail, 8 (80\%) utilizaram o recurso, enviando alguma mensagem ao grupo.

Os recursos online apareceram espontaneamente apenas na discussão sobre "aprender a conhecer". A possibilidade de "conhecer fontes científicas confiáveis", identificadas nas forças tarefas internacionais trabalhadas no curso presencial (U.S. Preventive Services Task Force e Canadian Task Force on Preventive Health Care) e demais fontes da webliografia sugerida, foi consenso entre os participantes dos três anos. A fala de uma das alunas resume esta categoria:

P5 (2006): "Outra coisa foi a utilização das referências teóricas. Vira e mexe eu vou para a internet ver se alguém já estudou o assunto que eu tenho interesse."

Todas as reflexões voltadas para o "aprender a fazer", "aprender a conviver" e "aprender a ser", obtidas nos três grupos, abordaram fatores da experiência de ensino presencial. A possibilidade de observar ações no Centro de Promoção da Saúde foi apontada como crucial para aplicação dos conhecimentos discutidos em aula.

Os depoimentos espontâneos sobre aprender a conviver ressaltam a oportunidade da convivência, em sala de aula, com pessoas de formação, interesses e posturas diferentes. Interessante notar que o produto principal da convivência foi a tolerância, atitude social de quem reconhece o direito dos outros manifestarem diferenças de conduta e de opinião. Em nenhum das falas encontramos o conceito de cooperação, colaboração, isto é, trabalho junto com outro ou outros para um fim comum.

Uma segunda categoria foi o impacto do aprendizado no ambiente e nas relações de trabalho. A 
aquisição de linguagem comum e a familiaridade com a promoção da saúde enriqueceram as trocas no trabalho, sobretudo para os participantes do grupo focal referente ao ano de 2007.

\section{Quantitativo}

Na Tabela 2 são apresentadas as participações dos alunos no blog e no grupo de e-mails nos dois anos consecutivos. Notou-se um aumento significativo, da ordem de $87 \%$, de participação no blog. Porém, o tempo médio das visitas e o número de páginas exibidas por visita não aumentaram, indicando que a procura continuou sendo rápida, objetiva e restrita a interesses específicos.

A participação no grupo de e-mails também cresceu cerca de 50\%, acompanhando a pró-atividade da tutoria; apesar de todos os alunos terem aceitado o convite para serem membros do grupo de e-mails, notou-se a participação ativa de apenas 27 alunos (36\%) em 2007 e de 43 (72,9\%) em 2008. A pesquisadora enviou 30 mensagens ao grupo, em 2007 e 62 em 2008.

O Gráfico 1 ilustra a utilização semanal do blog em 2007 e 2008, que foi considerada estatisticamente diferente ( $p<0,0001)$. O Gráfico 2 mostra que ao longo das primeiras 18 semanas dos dois anos estudados houve uma grande variação no envio de mensagens ao grupo de e-mails, também estatisticamente significante $(p=0,012)$.

Tanto no Gráfico 1 quanto no 2 observam-se picos de utilização na $7^{\text {a }}$ e $18^{\text {a }}$ semanas, do curso de 2008, relacionados ao período de avaliação dos módulos, com aplicação de provas e oferta das palavras cruzadas com os conceitos marcadores.

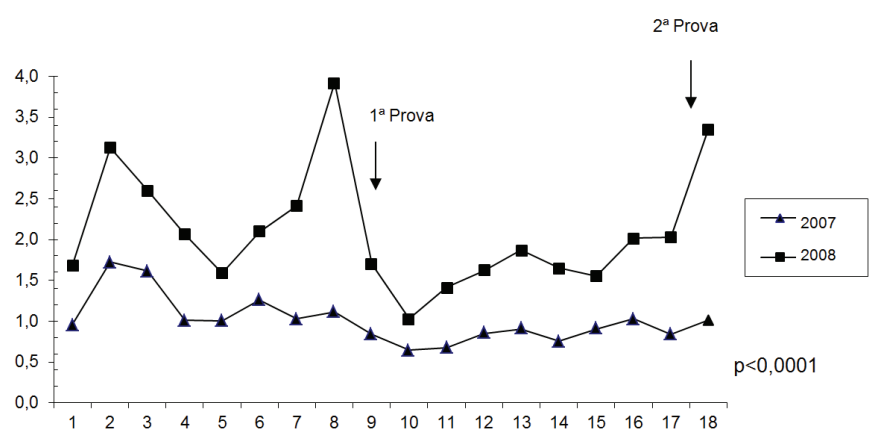

Gráfico 1. Número médio de visitas ao blog, por aluno, ao longo de 18 semanas

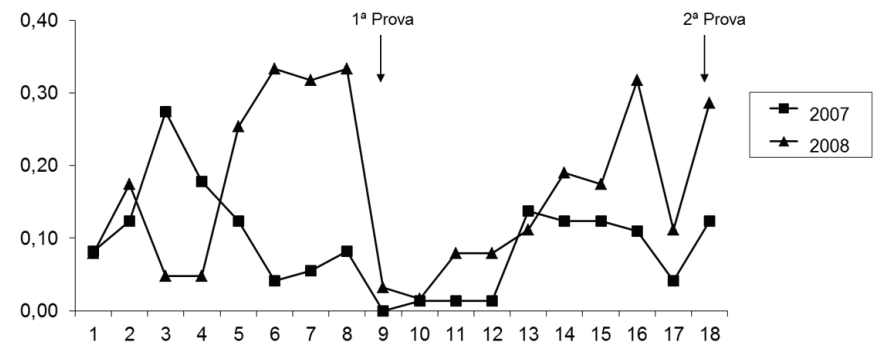

Gráfico 2. Número médio de mensagens enviadas ao grupo de e-mail, por aluno, ao longo de 18 semanas

\begin{tabular}{|l|c|c|}
\hline \multicolumn{2}{|l|}{ 2007 (N=75) } & 2008 (N=59) \\
\hline Blog & 1345 & 2519 \\
\hline Número total de visitas & 18.0 & 42.7 \\
\hline Méia de visitas por aluno participante & 2.4 & 2.4 \\
\hline Tempo médio das visitas (minutos) & 2.3 & 2.1 \\
\hline Número de páginas exibidas por visita & $25[33.3 \%]$ & $41[69.5 \%]$ \\
\hline Grupo de e-mails & \multicolumn{2}{|c|}{} \\
\hline $\begin{array}{l}\text { Número de alunos que } \\
\text { enviaram mensagens - N [\%] }\end{array}$ & 125 & 195 \\
\hline Número total de mensagens enviadas & $21[16.8 \%]$ & $42[21.5 \%]$ \\
\hline Número de mensagens de grupo temático - N [\%] & 30 & 62 \\
\hline Número de mensagens enviadas pela tutora & & \multicolumn{2}{|c|}{} \\
\hline
\end{tabular}

Tabela 2. Indicadores de utilização do blog e grupo de e-mails pelos alunos do curso de práticas de promoção da saúde, em 2007 e 2008. 
Resta descrever a utilização das enquetes colocadas no blog e das palavras cruzadas. Durante oito semanas de 2008, foram publicadas seis enquetes que receberam de $7(12 \%)$ a $27(46 \%)$ votos.

A contagem de downloads das palavras cruzadas, em 2008, mostrou 102 acessos ao formato zipado e 145 visitas para preenchimento online, nas primeiras oito aulas, o que corresponde a aproximadamente dois downloads por aluno. Já nas oito aulas seguintes, o número caiu para 56 acessos à forma zipada e 67 online, praticamente um download por aluno.

A análise das mensagens enviadas em 2007 mostrou que os principais temas foram as aulas presenciais, dúvidas sobre acesso aos textos complementares e sugestão de outros materiais. Em 2008, além da repetição de conteúdos do ano anterior, houve boa utilização dos espaços informais: "café virtual" - três mensagens; "cine pipoca saudável" - 25; e o "espaço caminhos e caronas" - sete mensagens.

O grupo temático (sugestão de questão teórica dada em aula para comentários práticos, estimulando a reflexão sobre um projeto comum) contou com 21 mensagens (16,8\%) em 2007 e 44 (21,5\%) em 2008.

A aplicação da análise proposta por Fernandes (2008) sobre os tipos de troca mostrou a substituição das trocas iniciais ou de continuidade restrita, predominantes em 2007 (65\%), pela troca em rede em 2008 (Tabela 3).

\section{Discussão}

Pode-se dizer que os recursos didáticos digitais usados podem ter contribuído para que os alunos dos cursos gerenciassem e construíssem um conhecimento adequado sobre as práticas clínicas de promoção da saúde. Entretanto, os resultados obtidos não permitem dizer se esta construção foi melhor ou mais fácil do que sem os mesmos.

\begin{tabular}{|l|c|c|c|c|c|}
\hline Tipo & $\mathbf{2 0 0 7}$ & $\mathbf{\%}$ & $\mathbf{2 0 0 8}$ & $\mathbf{\%}$ & $\mathbf{p}$ \\
\hline Troca Inicial & 29 & $22.48 \%$ & 25 & $12,38 \%$ & \\
\hline $\begin{array}{l}\text { Troca com } \\
\text { continuidade } \\
\text { restrita }\end{array}$ & 55 & $42.64 \%$ & 33 & $16.34 \%$ & 0.036 \\
\hline Troca em rede & 45 & $34.88 \%$ & 144 & $71.29 \%$ & \\
\hline
\end{tabular}

Tabela 3. Tipos de trocas identificadas nas mensagens compartilhadas pelos alunos e tutora, conforme proposto por Fernandes, 2008

De forma geral, a baixa utilização aparente dos recursos interativos pela população estudada deve-se ao fato da pouca intimidade do grupo com os mesmos. Seriam os "imigrantes digitais", definidos por Prensky (2007). Além disso, por serem profissionais já graduados, as jornadas de trabalho possivelmente extensas e cansativas podem limitar o tempo disponível a ser dedicado a estudos para aprimoramento. Isto pode ser evidenciado nos tempos médios de visitas e no número de páginas por visita, que foram baixos, indicando necessidade de rapidez e objetividade no acesso (Tabela 2).

A mesma tabela marca a diferença de utilização dos recursos digitais observada entre 2007 e 2008, sustentando a hipótese de que a tutora facilitou a aproximação e familiarização com novos recursos didáticos (Boulos et al., 2006). Com foco na formação de tutores na área médica, Trevena (2003) descreve que as principais características atribuídas a um tutor efetivo são a criação de um clima colaborativo entre o grupo de alunos, o interesse perceptível em ensinar e a habilidade para dar feedbacks úteis, todas estas colocadas em prática, ativamente, durante a edição de 2008 , dentro do projeto de estudo em discussão.

Vale destacar que a concentração significativa de acessos ao blog e de mensagens enviadas aos grupos de e-mails no período que antecedia às provas, ilustrado nos Gráficos 1 e 2, foi muito semelhante ao encontrado em outros estudos (Soares et al, 2003 e Galvão e Magalhães, 2009), ressaltando o importante 
papel que a proximidade da avaliação desempenha no estímulo à busca de material para aprimoramento e melhor preparo, visando à aprovação.

Hutchinson (1999) traça um paralelo entre pesquisas sobre intervenções clínicas e estudos na área da educação e aponta três dificuldades particulares ao segundo grupo: a natureza complexa da educação, influenciada por uma sinergia de fatores (dos alunos, da profissão, do tipo de intervenção educativa e dos impactos na sociedade); a questão da amostragem, muitas vezes pequena e as dificuldades de obtenção de grupo controle e a dificuldade para escolher e mensurar os desfechos de interesse.

Nessa direção, foram desafios e permaneceram como limitações do presente estudo: a heterogeneidade da amostra, formada pela demanda espontânea de alunos de diferentes edições dos cursos presenciais de promoção da saúde (atualização e especialização); a falta de ferramentas administrativas que permitissem o controle de acessos no blog e obtenção de estatísticas detalhadas sobre o uso do grupo de e-mail; baixa participação no OSCE, que não foi obrigatória, e que prejudicou a investigação do ganho de habilidades e a incapacidade de discriminar, através dos meios de mensuração usados, o meio pelo qual os alunos incorporam informações e constroem o seu conhecimento próprio, com e sem o uso dos recursos didáticos digitais.

\section{Conclusão}

Do ponto de vista qualitativo, o uso dos recursos digitais mostrou-se útil para auxiliar na ressignificação da estrutura e do modelo do ensino tradicional, e, segundo os depoimentos dos alunos participantes, contribuiu para a aprendizagem na dimensão do aprender a conhecer. A avaliação na forma de provas de múltipla escolha foi relevante para aumentar a utilização do blog e do grupo de e-mails.

A utilização de recursos digitais pelos alunos foi marcada pelo interesse focal no conteúdo trabalhado, em detrimento das dimensões mais interativas, que estimulam o aprender a conviver. Entretanto, e a tutoria proativa de 2008 contribuiu para "troca em rede" (todos escrevendo para todos) no grupo de e-mails.

\section{Referências}

1. Dowbor FF, Carvalho S, Luppi D. Quem educa marca o corpo do outro. São Paulo: Edta Cortez; 2007.

2. Delors J. Educação: um tesouro a descobrir. $8^{\circ}$ edição. São Paulo: Cortez.2003

3. Brasil. Portaria GM/MS n 1.996 de 20 de agosto de 2007. Dispõe sobre as diretrizes para a implementação da Política Nacional de Educação Permanente em Saúde. DOU, Brasília, DF, n. 162, 22 ago. 2007.Seção I

4. Ebert CRC. O ensino semi-presencial como resposta às crescentes necessidades de educação permanente. Educar. 2003;(21):83-98

5. Silva, ACCG. Educação apoiada em tecnologias: desenvolvimento e avaliação de recursos didáticos para a formação de promotores de saúde Tese (Doutorado). Faculdade de Medicina da Universidade de São Paulo -- São Paulo, 2009.181 p.

6. Minayo MCS; Sanchez O. Quantitativo \& qualitativo: oposição ou complementariedade? Cad Saúde Pública.1993; 9 (3): 239-262,.

7. Serapioni M. Métodos qualitativos e quantitativos na pesquisa social em saúde: algumas estratégias para a integração. Ciência \& Saúde Coletiva, 2000; 5 (1): 187-192.

8. Lüdke M, André MEDA. Pesquisa em educação: abordagens qualitativas.São Paulo. Edta Pedagógica e Universitária Ltda. 4a edição 1988.

9. Alves-Mazzotti, A.J. Relevância e aplicabilidade da pesquisa em Educação. Cadernos de Pesquisa. 2001; 113: 39-50.

10. Carlini-Citrim B. Potencialidades da técnica qualitativa grupo focal em investigações sobre abuso de substâncias. Rev. Saúde Pública, 1996 30(3): 285-293.

11. Weller W. Grupos de discussão na pesquisa com adolescentes e jovens: aportes teórico-metodológicos e análise de uma experiência com o método. Educação e Pesquisa, 2006; 32: 241-260.

12. Gondim, SMG. Grupos focais como técnica de investigação qualitativa: desafios metodológicos. Paidéia. 2002;12(24):149-161.

13. Iervolino,SA ; Pelicioni, MCF. A Utilização do Grupo Focal como Metodologia Qualitativa na Promoção da Saúde. Rev Esc Enferm USP. 2001; 35 (2): 115-121.

14. Fernandes AAP.As trocas interindividuais em fóruns e listas de discussão: um estudo de caso no âmbito da pedagogia em EaD. [dissertação de mestrado]. Porto Alegre: Faculdade de Educação: Universidade Federal do Rio Grande do Sul. 2008.126p

15. Prensky, M. (2001). Digital natives, digital immigrants. [on-line]. Disponível em http:// www.educause.edu/ir/library/powerpoint/SAC0504.pps [Consultado em 10/8/2009].

16. Boulos MNK, Maramba I, S. Wheeler. Wikis, blogs and podcasts: a new generation of Web-based tools for virtual collaborative clinical practice and education. BMC Med Educ. 2006, 6:41 
17. Trevena $L$. What medical students value in a population health tutor: characteristics for consideration in staff recruitment and development. Education for Health 2003;16(1):51-58

18. Soares A.A.G, Dias, C.P, Vidal E.O, Coeli C.M, Almeida L.M, Camargo Jr KR. Utilização de um Serviço de Monitoria Virtual Voltado para o Ensino de Epidemiologia na Graduação Médica PHYSIS: Rev. Saúde Coletiva, Rio de Janeiro, 13(1):39- 58, 2003
19. Galvão MF, Magalhães AV. Sistema de Apoio à Aprendizagem da Disciplina Medicina Legal e Deontologia Médica na Universidade de Brasília. Rev Bras Educ Med, 2009; 33 (1):84-91.

20. Hutchinson L. Evaluating and researching the effectiveness of education interventions. BMJ. 1999; 318:1267-1269. 